\title{
Pneumobilia with Diaphragmatic Rupture Following Blunt Trauma
}

\author{
Dong Hun Kim, Hancheol Jo, Seokho Choi \\ Department of Surgery, Trauma Center, Dankook University Hospital, Cheonan, Korea
}

Pneumobilia is the presence of gas in the biliary tree, mostly caused by biliary-enteric surgical anastomosis or a biliary intervention. Pneumobilia following abdominal trauma is extremely rare. Here we report pneumobilia accompanied with left diaphragmatic rupture following blunt trauma in a 57-year-old woman involved in a motor vehicle accident.

Key Words: Air; Biliary; Diaphragm; Blunt; Trauma

(Trauma Image Proced 2017(2):66-68)

\section{CASE}

A 57-year-old woman sustained blunt trauma from a traffic accident and had abdominal pain with dyspnea. A supine chest X-ray showed soft tissue density in the left chest (Fig. 1). A chest computed tomography (CT) scan revealed a left diaphragmatic rupture with the stomach herniated into left pleural cavity and air in the biliary tree (Fig. 2A). An abdominal CT scan revealed the air distributed through the biliary tree corresponded to couinaud segment IV (Fig. 2B and 2C). She had not undergone a biliary surgery or biliary intervention. On arrival, she did not have a small bowel obstruction and did not present any infection-related symptoms or signs. She discharged without any further evaluation with the management of pneumobilia in postoperative day 12 , after emergency laparotomy with hernia reduction of the stomach and primary repair of left diaphragm.

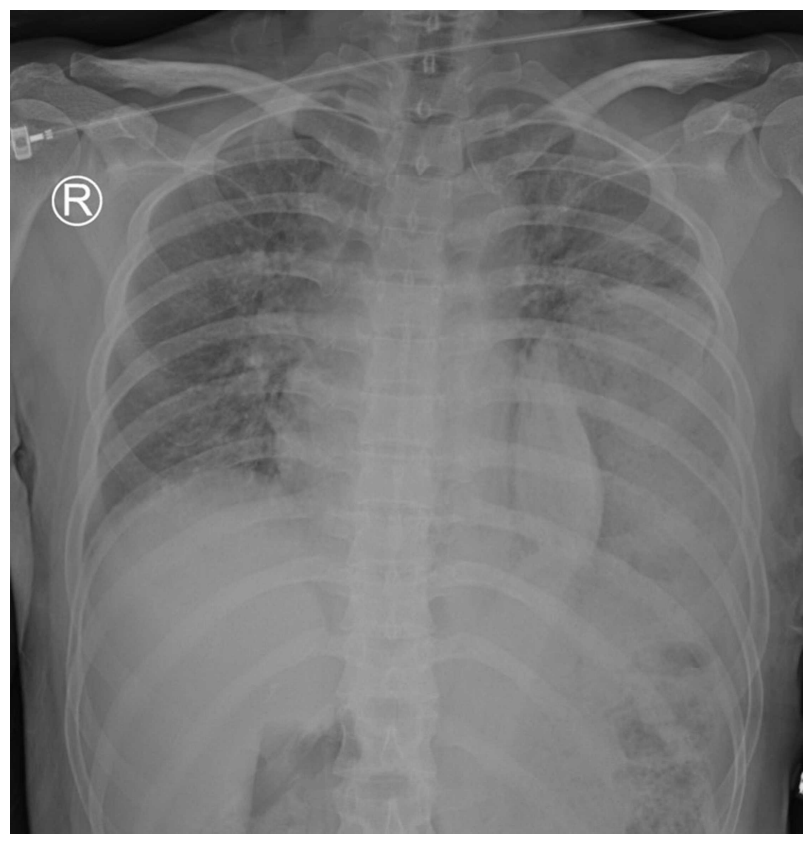

Fig. 1. A supine chest radiography showed the soft tissue density suggesting diaphragmatic hernia in the left lower chest.

Received: September 7, 2017 Revised: October 23, 2017 Accepted: November 10, 2017

Correspondence to: Dong Hun Kim, Department of Surgery, Trauma Center, Dankook University Hospital, 201 Manghyang-ro, Dongnam-gu, Cheonan, Chungnam 31116, Korea

Tel: 82-41-550-7661, Fax: 82-41-550-0039, E-mail: saint7331@gmail.com

Copyright (c) 2017 Korean Association for Research, Procedures and Education on Trauma. All rights reserved.

@This is an open-access article distributed under the terms of the Creative Commons Attribution Non-Commercial License (http://creativecommons.org/ licenses/by-nc/4.0) which permits unrestricted noncommercial use, distribution, and reproduction in any medium, provided the original work is properly cited 

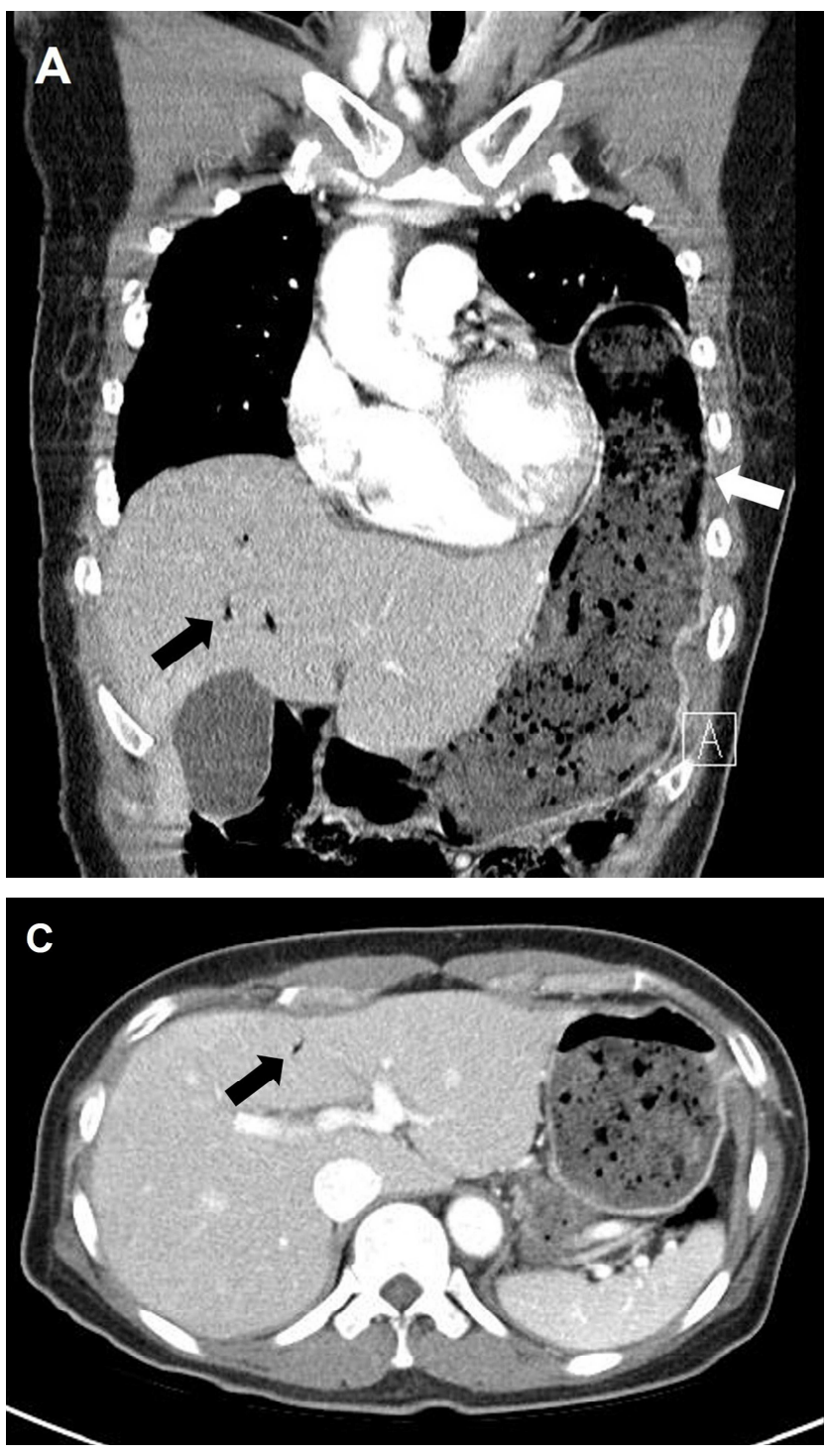

DISCUSSION

Pneumobilia is defined as the presence of gas in the biliary system. The most causes of pneumobilia are biliary surgery, a biliary intervention such as endoscopic retrograde cholangiopancreatography, gallstone disease, or biliary-enteric fistula (1). Pneumobilia is a rare radiographic finding after blunt trauma to the abdomen. The diagnosis of pneumobilia reported most were confirmed by a CT scan (2-5), as is the case herein. High impact pressure of blunt trauma is thought to force gas from the duodenum through the sphincter of Oddi and into the biliary system, resulting in diaphragmatic

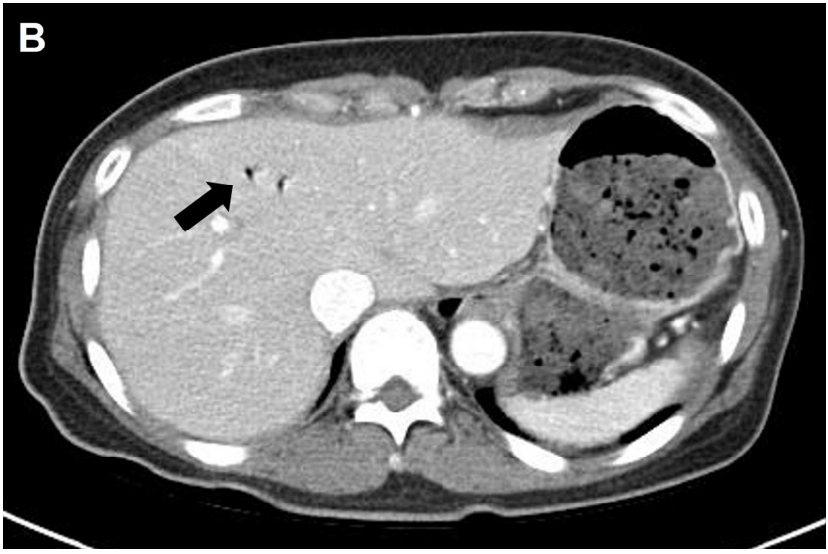

Fig. 2. A computed tomography scan shows that (A) pneumobilia (black arrow) is detected with traumatic diaphragmatic injury and stomach herniation (white arrow) in the coronal view, (B) and (C) pneumobilia (black arrow) is confirmed along the biliary tree of Couinaud segment IV in the axial view.

rupture. Although pneumobilia with additional clinical findings may necessitate further evaluation, in the absence of any evidence of infection it seems to be a self-limited condition which can be managed conservatively without operation (2-5).

\section{Conflicts of Interest Statement}

None of authors have a conflict of interest.

\section{REFERENCES}

1. Yamashita H, Chijiiwa K, Ogawa Y, Kuroki S, Tanaka M. The internal biliary fistula--reappraisal of incidence, type, 
diagnosis and management of 33 consecutive cases. HPB Surg 1997;10:143-7.

2. Thompson RJ, Irwin T. Pneumobilia following blunt abdominal trauma. Ir J Med Sci. 2007;176:313 - 315.

3. Yıldız F, Coban S, Terzi A, Cece H, Uzunkoy A. An uncommon cause of pneumobilia: blunt abdominal trauma. Ulus Travma Acil Cerrahi Derg. 2011;17:363 - 364.
4. Barnes SL, Badrudduja M, Bernard AC, Boulanger BR. Pneumobilia after blunt trauma: a self-limited condition? J Trauma. 2006;60:637 - 639.

5. Okan İ, Tali S, Özsoy Z, Deniz Ç, Acu B, Yenidoğan E, et al. The development of pneumobilia after blunt trauma. Turkish Journal of Surgery/Ulusal cerrahi dergisi. 2016; 32(3):224-225. 